\title{
7
}

\section{Evaluating the partnership research process}

\author{
Jean-Marc Fontan and Denis Bussières \\ Translation by Elizabeth Carlyse
}

As part of the project Strengthening Knowledge Strategies for Poverty Alleviation and Sustainable Development: A Global Study on Community-University Partnerships, the team at l'Université du Québec à Montréal (UQAM, www. aruc-es.uqam.ca) was given the task of developing an evaluation process for research partnerships. First, a definition of partnership research was developed. Second, the concept of evaluation is discussed and an attempt made to differentiate the partnership process from the process of social change in which research partnerships usually take place. Finally, a partnership research evaluation model, grounded in participating practitioners' point of view, is proposed.

\section{The project}

This project has five main goals:

1 to provide examples of partnerships between community organizations and universities;

2 to identify institutional arrangements between universities and community organizations that facilitate productive partnerships;

3 to make policy recommendations to national and international organizations, with the aim of providing better support for research partnerships;

4 to make suggestions to UNESCO and other international agencies, with a view to stimulating participation in research partnerships; and

5 UQAM's participation.

The UQAM team, led by Jean-Marc Fontan, was given the task of identifying indicators of success in research partnerships. While collaborative research partnerships have been in place for several years in universities in Canada and around the world, little has been written on evaluating this research model.

First, this chapter seeks to define partnership research. Second, we focus on evaluation of the partnership research process, an undertaking distinguished from analysis of the larger process in which partnership research takes place. Finally, a partnership research evaluation model, based on the partnership research model developed by the Alliance de recherche universités-communautés en économie sociale (ARUC-ÉS, or CURA on the social economy) and the Réseau québécois 
de recherche partenariale en économie sociale (RQRP-ÉS), was proposed (two projects that received funding from SSHRC from 2005 to 2010).

\section{A definition}

Generally, when one speaks of partnership research, one is referring to research undertaken jointly by researchers and practitioners. To fully understand the concept of partnership research, one must go beyond the simplistic notion implied and describe the research more concretely. There is no consensus around the term partnership research. Depending on researchers or disciplines, it may also be called action research (recherche-action), collaborative research (recherche collaborative), or participatory research (recherche participative). Some call it interventionist research (recherche-intervention), collaborative learning (apprentissage collaboratif), or training research (recherche-formation) (Couture et al., 2007).

All terms embody the dynamism of this movement that seeks to 'link theory and practice, to take into account the voice of practitioners or local players in the generation of a certain knowledge of their practice' (ibid.). The same dynamic language appears in English; one speaks of 'community-based research, 'community-based participatory research', and 'community-university partnerships'. Putting differences aside, all of these forms of research seek to break the traditional research mould, where participants are merely research subjects. These community-oriented research methods also subscribe to and participate in change in practices and social change.

Throughout this chapter, for the terms ARUC-ÉS and RQRP-ÉS partnership research will be used.

\section{Research initiated by practitioners}

In partnership research, research questions come from the field. Practitioners are at the heart of defining these questions, as opposed to traditional university research, where hypotheses are generated by scholarly study. As the website of the Office of Community-Based Research, University of Victoria (www.communitybasedresearch.ca/Page/View/CBR_definition.html) emphasizes, a research partnership 'begins with a research topic of practical relevance to the community (as opposed to individual scholars) and is carried out in community settings'.

Research partnerships are embedded in the questions that arise in the field, and necessarily focus on questions arising from the application of knowledge. Thus, the practitioners participate in the formulation of research objectives. Partnership research implies the 'the co-construction by a researcher and a practitioner of a research goal' ${ }^{1}$ (Desgagné, 1997). It is not simply a matter, therefore, of problematizing issues that arise in the field, but of building, together, a research question. 


\section{Co-construction of knowledge}

Practitioners not only define research goals, they also play an active role in the process of generating knowledge. In one sense, they also become knowledge producers. As Desgagné notes, 'these practitioners become, at some point or other in the research process, "co-creators" of the knowledge sought vis-à-vis the research goals' (ibid., pp. 372-3).

This participation in the process of knowledge creation is therefore a fundamental characteristic of partnership research: 'participation in the products and process of research by people who experience the issue being studied is considered fundamental to CBPR' (Viswanathan et al., 2004). Partnership research is identified by research conducted with the partners or the communities, rather than about the partners or the communities.

Here, it is important to distinguish partnership from collaboration. Collaboration limits the role of participants to 'facilitating the collection of data, the recruitment of subjects, access to archives, access to statistics' (Simard, 2001, free translation from French), and aims to create the conditions required by the researcher in a given milieu. In contrast, partnership implies greater involvement of practitioners in the entire research process. This process includes identifying target populations, involvement in the creation of tools for gathering data and participation in the analysis of the findings and the drafting of any reports.

\section{Mobilisation of knowledge}

Partnership research also differs from traditional research when it comes to disseminating findings. In traditional research, the dissemination of research findings is sometimes limited to academic journals, while, in partnership research, practitioners play a key role in the communication of research results to peers. For this reason, they participate in the development of communication tools, the identification of target audiences and even the dissemination itself (PowerPoint presentations, colloquia, seminars). In a partnership research, the different organizations that participate are expected to assimilate research findings so that this knowledge can be used to influence, modify or even overhaul practices.

Partnership research differs at every stage from traditional research, whether at the point of defining the object of study, in the research process, or in the application of knowledge by the participating organizations.

\section{The challenge of evaluating research partnership}

\section{Evaluation}

To tackle the question of evaluation is to venture onto a path littered with obstacles. The evaluation process exposes questions of methodology (how to evaluate); political problems (by whom and for whom); and ethical problems (whose values underlie the act of evaluating). Over the years, the methods and objectives specific to evaluations have evolved: 'over the past two centuries, evaluation, in education 
and other domains, has undergone a profound transformation: as a result of public scrutiny, evaluation now constitutes an autonomous discipline with precise rules and methods' (Fontan and Lachance, 2005, p. 4).

In their book Fourth Generation Evaluation, Guba and Lincoln (1989) propose dividing the evolution of evaluation into four generations, with each generation characterized by a distinct concern or perspective. According to Fontan and Lachance (2005, p. 4), a fifth generation is 'based on the recognition of its raison d'être and on the support given to it by the community'. For this chapter's purposes, these interesting debates will be set aside, and we will return to the basic principles that will guide the present discussion.

To evaluate is to pass judgement, with reference to a model or an objective that serves as the basis for the evaluation. 'This judgement allows for the measurement of a gap, whether or not it exists, between a given, very real situation, and the expected or desired situation' (Fontan, 2001, p. 12, free translation from French). As far as we are concerned, it is a matter of passing judgement on the research partnership process and its results. To evaluate, 'data collection must be methodical and comparisons must have a referent' (Centraide du Grand Montréal, 2004). Based on the research partnership model developed at ARUC-ÉS and RQRP-ÉS (2007b), a questionnaire that allows for the collation of information on the research process and results is posited.

The research framework proposed here does not call for external evaluators, but rather rests in the hands of the partners in the partnership research. It is an 'analytical evaluation [framework] ... more useful for controlling and improving its own work' (Hiernaux, 2001, p. 84), and 'should allow for the transfer what is known about one experience to another experience or to actions in the same domain' (p. 84).

Before getting to the heart of the proposal, it is important to distinguish the partnership research evaluation process from the process of change in which it is embedded.

\section{Partnership research is part of a broader process}

As has been emphasized above, partnership research is part of a broader process that, ultimately, seeks to make change: changes in practice, political change (advocacy), or social change (improvement of health, living conditions, etc.). The expectation for change far surpasses the research objectives specific to the research partnership, and involves different participants and actions that differ from the basic research process. Some of these include community facilitation, training, citizen action and the formation of coalitions with others in the community who are not involved in the research.

Figure 7.1 illustrates the integration of partnership research into a process of change.

In Figure 7.1, the large circle represents the change desired by the organization or the community, and the small circles represent the different actions that could lead to this transformation. Of note, partnership research is only one of the elements needed to achieve the desired change. To evaluate the desired change 


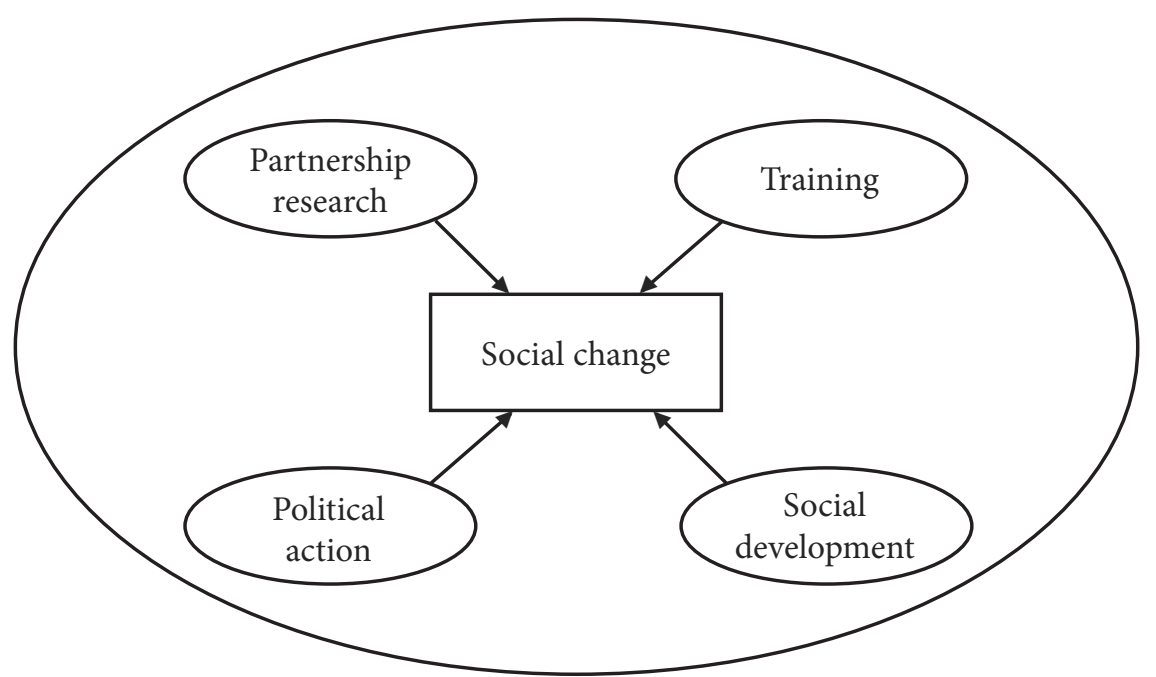

Figure 7.1 Integration of partnership research into a process of change

becomes a much more involved process, one in which it is important to determine the particular contribution made by the research project.

\section{Two examples}

Example 1: in a study of laws governing property assessments for recreational organizations, research was conducted to examine the assessment tables for different municipalities, with the goal of identifying any errors and inconsistencies in the application of laws. The participating organization's goal was to propose changes to relevant legislation to ensure equitable application in all jurisdictions.

It is clear that even if the research is undertaken in partnership and the results show mistakes in the application of the law, the goal of legislative change requires more resources than just research results (political pressure, meetings with elected officials, participation in coalitions). To evaluate the partnership research on whether or not the laws are changed would be to base this evaluation on research elements over which it has little or no control. Here, the research project is only one of several elements that support the process of change.

Example 2: as part of a campaign to fight marginalization and poverty in one area of a municipality, a study was undertaken with residents to identify their perception of the problems in the area, to understand their expectations for changes to be made in the social fabric and urban geography of their community. The goal for the organization participating in the research is, ultimately, to put in place a citizens' committee that could take the concerns of the residents and implement practical solutions to the problems identified in the survey.

Once again, it is clear that the research is taking place within a wider sphere. The research project is just one of the elements that will inform the work of campaign organizers. Ultimately, solutions to the problems experienced by the residents of 
the area will require actions that go beyond the results of the partnership research.

When one speaks of evaluating partnership research, it seems essential to distinguish this evaluation from the evaluation of the broader process of which the research partnership is a part. Without exception, partnership research provides only a snapshot of a much bigger and more complex process. To confuse these two evaluations is to not do justice to the process specific to the partnership research. In a sense, this would give the partnership research impossible powers and goals. It also ignores the fact that it 'must be possible to attribute [change] to action; in other words, [change] occurs because of [the action]' (Centraide du Grand Montréal, 2004). Thus change, in particular, social change, requires many and complex actions. This explains why evaluating social change is so difficult.

For this reason, it is important to differentiate the evaluation of the partnership process from the evaluation of the goal for change that is the overarching motivation for the partnership research. In the following section, a procedure for evaluating partnership research is proposed.

\section{Evaluation of the partnership process}

To evaluate partnership research, one must get to the very heart of the research process in order to understand the different moments and actions that result in its successful completion. A paper entitled 'La recherche partenariale: Le modèle de l'ARUC-ÉS et du RQRP-ÉS' (ARUC-ÉS and RQRP-ÉS, 2007b) provides inspiration. The part of this evaluation model that addresses the impact of the research on the practitioner or organization participating in the research is employed here. A parallel process could also be put in place to evaluate the impact on researchers, students or the university as a whole.

\section{Research phases}

As noted earlier, partnership research is defined by three essential steps or phases: the co-definition of research goals; the co-implementation of the research project; and the mobilization of the resulting knowledge. Each of these phases must be deconstructed, to determine the actions required for the project to be successful.

\section{Co-definition of the research project}

Deconstruction involves posing a series of questions for each phase. The answers to these questions allow for the formulation of an opinion as to whether the partnership process has been a success or failure.

The first question goes back to the start: who initiated the project? Was it the practitioners or researchers who made the initial request? Next, it can be asked: how will this project contribute to the work of practitioners? Does this project aim to support a process of awareness raising, training, social change or change in practices? Will this project allow the participating organization to better understand the socio-political landscape? All these questions aim to anchor the project in the needs in the field. Usually, if the project is well grounded in the field, the spin-offs can be anticipated from the very beginning. 
Once the beginning phase is complete, it is time to think about project oversight. Will a working group comprised of researchers and practitioners be established in order to ensure the project is carried out? Has this working group been involved in defining the project and establishing the research plan? How will decisions on managing financial and other resources be made?

The definition phase, including the establishment of a research team, is crucial. It is at this moment that a climate of trust is established between the partners. This phase paves the way for the smooth implementation of the project. The initial entente provides the foundation on which the partners can lean if tensions arise in the course of the project.

\section{Co-implementation of research}

Once again, a series of questions allows for a more concrete assessment of the participation of practitioners in the implementation of the research project. Did the practitioners take part in the determination and implementation of the research tools (questionnaires, identification of the target audience, surveys)? Did they take part in analyzing the findings, drafting research reports and drafting the final report? Questions could also be asked about the number of working group meetings and whether the participating organizations integrated the researchers and students into the research process.

\section{Mobilisation of knowledge}

The mobilisation of knowledge can be examined on two levels. The first is concerned with diffusion of research results and the second, the transfer of knowledge, speaks to the transformation of new knowledge into practice.

As with the other phases, it is a matter of determining the effective participation of practitioners in knowledge mobilisation. Did the practitioners participate in the implementation of the communication tools and the identification of target audiences? Did they take part in the development of strategies for disseminating information? Did they collaborate in the communications work? Did the participating organization contribute logistically, financially or in other ways?

\section{The results}

Research partnerships are not just about process - each research project has its own objectives: profiling an issue; a study of a certain population; or a balance sheet. In fact, there are as many research topics as there are specific objectives in each research project. These results must not be left out of the evaluation, as they form the basis of the partners' requirements, and they will play a role in the broader process of change of which research partnerships are part.

Research results can be seen as internal to the research, or external, linked to the social change in which they are embedded. Internally, has the research met the expectations established at the outset? Have the deliverables materialized (book, manual, summary, synthesis, etc.)? Was the partnership process satisfactory in terms of relationships? 
Table 7.1 Evaluation of partnership research

\section{Co-definition phase}

Activities

Yes No

Participation of practitioners in defining the project

Participation in establishing project goals

Participation in drafting a research method

Identification of potential practical applications

Establishing a working group

Participation in financial management

\section{Research co-implementation phase}

Activities

Yes No

Participation in defining the research tools (questionnaire, audience)

Analysis of results

Draft report-writing

Final report-writing

Researchers integrated into the organization

Regular meetings of the working group

\section{Knowledge mobilisation phase}

Activities

Yes No

Participation in developing communications strategy

Participation in developing communication tools

Identification of target audiences

Participation in dissemination activities

Logistical support from organization

Regular meetings of the working group

Research

Yes No

Meets expectations

Produces deliverables

Satisfied with the research partnership process

Results are useful

Results are being used

Has a positive effect on the area targeted for change 
Externally, there is the question of whether the research is useful. Were the participants able to use the results? And, finally, did the results make a significant contribution to change?

This series of questions regarding the different phases of research partnerships and their results is synthesized in a table that can also be used to evaluate these partnerships.

\section{Proposed evaluation model}

Based on the questions raised above, we propose a tool for evaluating the true participation of practitioners in the partnership research process (Table 7.1 and Figure 7.2). It is in a yes/no format, in order for the questionnaire to be easy to complete. Note that this questionnaire is designed to evaluate both the participation of practitioners and whether the expected results in the process of change have been achieved.

Accounting for the number of 'yes' answers for each part of the evaluation, we can distribute them in a space delineated by the three conditions required in a research partnership, as well as its results. We call this the partnership research space.

By counting the 'yes' responses for each of the four dimensions along the four directions created by the two axes, we can evaluate how any given research project corresponds to the research partnership model. That is, we can determine where a project falls in the research partnership space by responding to the three conditions and by the presence of positive results for practitioners. In this way, we can identify the most successful research projects and those that require improvement.

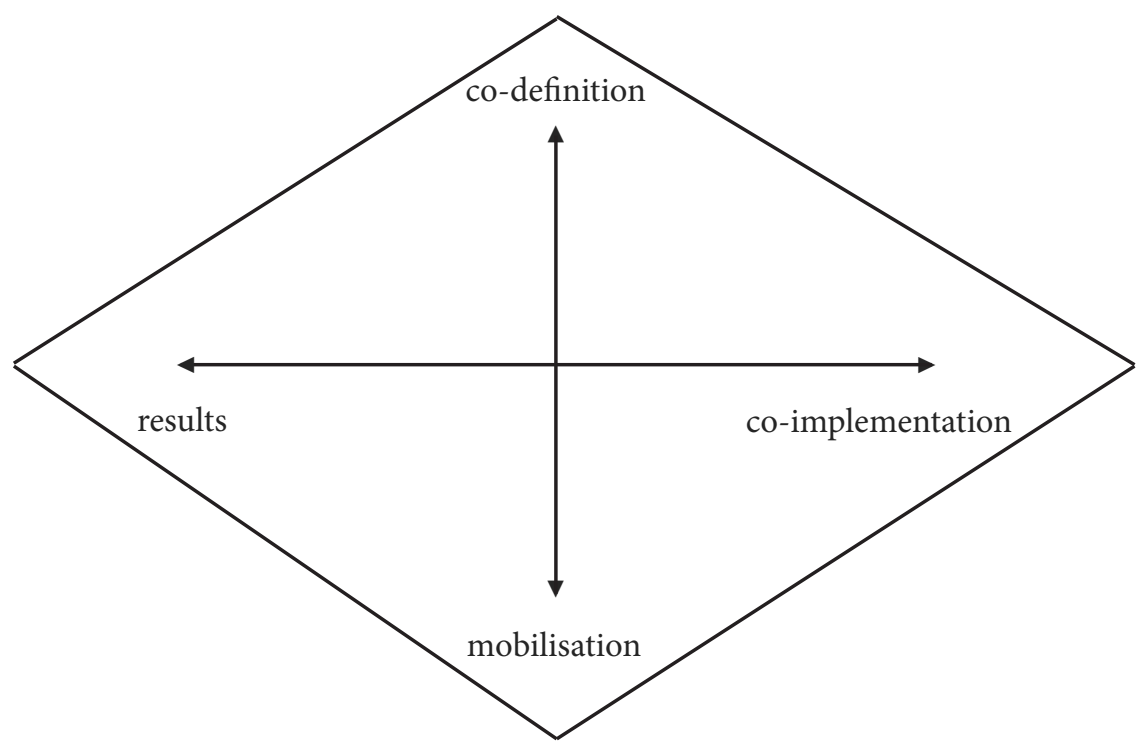

Figure 7.2 Partnership research process 
Using Table 7.2, which shows the results for three research projects, we can map out the place occupied by each of them in the partnership research space.

Analysing Figure 7.3, we can see that research Project A is very successful in terms of co-definition, and that it also surpasses the other two projects when it comes to co-implementation. It received the same score in the area of mobilisation as research Project B, and it has the strongest results. For each research project, we can see the strong points and the areas for improvement. Clearly, as illustrated in Figure 7.3, research Project $\mathrm{C}$ is a difficult fit for the partnership research model.

Table 7.2 Results from research projects

\begin{tabular}{lccc}
\hline Phases & Research Project A & Research Project B & Research Project C \\
\hline co-definition & 6 & 4 & 3 \\
co-implementation & 5 & 4 & 4 \\
mobilisation & 5 & 5 & 3 \\
results & 4 & 3 & 2 \\
\hline
\end{tabular}

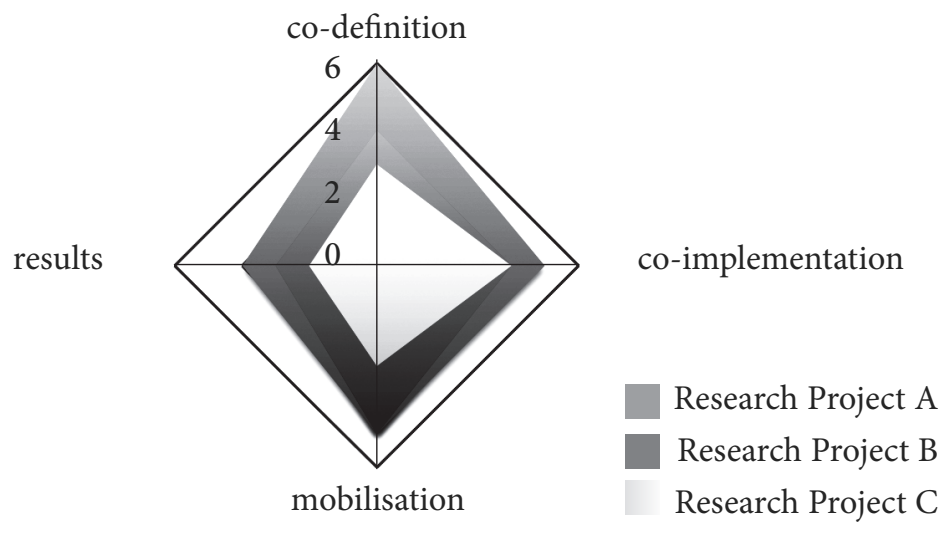

Figure 7.3 Three projects

This proposed tool for partnership research can be improved and detail can be added. In this way, a version could be developed to include the academic aspects of the project, thus allowing for, among other things, an evaluation of the impact of the research on students' learning, of publication in scientific journals, and of its contributions to the university community. Our model focuses, above all else, on the main steps in a partnership research from the point of view of practitioners. 


\section{Conclusion}

The partnership research movement is gaining strength in the Americas and elsewhere. As part of the Strengthening Knowledge Strategies for Poverty Alleviation and Sustainable Development: A Global Study on Community-University Partnerships project, it seemed important to submit for review and critique a model by which to evaluate research partnerships, from the point of view of the practitioners. It seemed important to differentiate the evaluation of the work from the process of social change in which research partnerships find themselves. Primarily, the model is targeted at the participants in partnership research, to give them tools with which to reflect on their partnership research experience and identify areas for improvement.

\section{Note}

1 Note that Desgagné here uses the term collaborative research for what we call partnership research. 